\title{
EL PROCESO PENAL ALEMÁN. INTRODUCCIÓN Y NORMAS BÁSICAS, JUAN LUIS GÓMEZ COLOMER
}

\author{
Sergio Peña Neira
}

Juan Luis GÓMEZ COLOMER (prólogo del profesor Dr. Hans Heinrich Jeschek), El proceso penal alemán. Introducción y normas básicas (Bosch, Barcelona 1995), 629 pp.

Es conocido el que el camino a Alemania ha sido transitado en múltiples oportunidades por juristas de diversas nacionalidades a fin de abrevar en las aguas que siempre frescas aunque tormentosas, trae el Derecho penal y procesal alemán. Este fue el caso, referido por mi profesor Dr. Manuel de Rivacoba, del penalista español Luis Jiménez de Asúa y asimismo por profesor Dr. Gómez Colomer.

Friburgo en Brisgovia, una ciudad y una universidad conocida por sus interesantes y profundos debates filosóficos, alberga hoy día un lugar muy importante para quienes deseen seriamente dedicarse a investigar el área de lo procesal penal. Allí se encuentra el Instituto Max Plank para el Derecho penal y procesal penal internacional. Es allí donde efectuó la investigación de más reciente data sobre la Ordenanza Procesal penal alemana que tengamos noticia y que procedemos a reseñar.

El trabajo en cuestión consiste en una traducción y un trabajo complementario de explicación de dicha Ordenanza efectuado por el profesor Gómez Colomer. Dicha traducción es la referida a la Ordenanza en su versión de 1985. Otra interesante traducciones, desfasada sin embargo del actual texto, es la del profesor Julio B Maier de la Universidad de Buenos Aires.

Formalmente son diez y nueve capítulos los que tratan el tema. En cada título del capítulo correspondiente se incorpora un sumario de temas y una lista bibliográfica particular (p. 12). Inicia la obra una clara y profunda introducción al proceso penal (p.39) y acompaña a la misma los principios procesales penales ( $p .43$ ) el material probatorio (p. 127). La segunda parte aborda el tema de la ley procesal penal (p.259) incorporándose en la tercera las leyes complementarias a la ley procesal penal (p. 437). La cuarta parte incluye un índice analítico (p. 527) y la quinta un interesante diccionario jurídico procesal penal (p. 601).

Temas de la reseña

La reseña que hemos decidido efectuar contemplará tan sólo los temas relativos a la iniciación del proceso penal y la valoración de la prueba.

Breve exposición sobre el proceso penal alemán

A fin de poder entregar en su totalidad el concepto de iniciación y prueba en el proceso penal, en este caso, alemán, sin lugar a dudas interesará, por las connotaciones prácticas, una breve exposición del procedimiento penal alemán. Innecesario es recordar que una de las fuentes que se ha tenido en la redacción de la actual modificación al código de procedimiento penal chileno es la Ordenanza procesal penal alemana. 
El procedimiento penal ordinario se divide en su totalidad en una fase declarativa y en una fase de ejecución (p.231). La fase declarativa puede realizarse a través del procedimiento ordinario o a través de procesos especiales. La ejecución es común, cualquiera sea el procedimiento empleado.

La fase declarativa, a su vez, consta de tres momentos o procedimientos que tienen vida propia. Las funciones de cada uno son diferentes:

1) El procedimiento preparatorio

Es la fase de averiguación y tiene por finalidad investigar todas las circunstancias que rodean la comisión de un hecho punible. Deben ser de importancia para poder establecer en su momento un juicio de valor acerca de la posibilidad de acusar o no a determinadas personas. Se averigua el hecho y se prepara la acusación (p. 232).

En este período la competencia para conocer y ejecutar la investigación la tiene el Ministerio Público. El Ministerio Público es una autoridad de la Administración de Justicia cuya característica es la autonomía y se encuentra dentro de la misma ( $p .70)$. No es una autoridad judicial ( $p .70$ ), por lo tanto no es parte en el proceso penal ( $p$. 71) y en caso de existencia de un hecho punible está obligado en principio a presentar la acusación (p. 7l).

El órgano jurisdiccional, en este momento o procedimiento. sin embargo, no se encuentra totalmente excluido y se presenta en la forma de un juez investigador quien debe acordar la prisión provisional, el registro domiciliario, las extracciones de sangre, etc.

Al término de este procedimiento el Ministerio Público debe llegar a una de estas dos conclusiones :

a) Acusa a una persona de la comisión de un hecho punible dado que existen fundamentos para sospechar del mismo, en cuyo caso debe ejercer el derecho de acción penal presentando el escrito de acusación.

Si opta por este camino debe pasar a la etapa intermedia. proceso.

b) No acusa en virtud de que no hay hecho punible en cuyo caso archivará el

2) El procedimiento intermedio

Este procedimiento es de competencia del órgano jurisdiccional. Comienza con la presentación del escrito de acusación el cual debe comunicarse inmediatamente al acusado. El órgano jurisdiccional debe determinar si procede seguir adelante con la acusación. De ser así, se entra en el llamado procedimiento principal o, al contrario, se procede a archivar el proceso. El acusado puede formular objeciones y reclamaciones tanto sobre el propio escrito de acusación, como sobre el posible auto de apertura del procedimiento principal posterior. También puede demandar la práctica de pruebas provisionales en apoyo de sus impugnaciones (p. 233).

Existe una fuerte crítica por la doctrina procesal alemana dado que el control o filtro que supone, implica un serio peligro de prejuzgar el juicio definitivo proponiéndose, según el profesor Gómez Colomer, su desaparición (p. 234).

3) El procedimiento principal 
Se inicia con el auto de apertura del procedimiento principal se divide en dos grandes momentos :

La preparación de la vista principal

La vista principal (p. 234).

No nos detendremos en la preparación de la vista principal dirigiéndonos, en forma inmediata, a la vista principal misma.

La vista principal, cronológicamente ordenada, se divide en :

Llamada a la causa. El presidente del órgano jurisdiccional llama a todos los participantes en este proceso penal y al público general.

Interrogatorio personal.

El Ministerio Público lee la "frase de acusación".

Luego se procede al interrogatorio del acusado.

Se continua con la práctica de la prueba.

Se entregan informes finales.

La vista se cierra con la última palabra del acusado.

Por último la subfase concluye con la sentencia (p. 235). Existe, por cierto, una fase de impugnación y de ejecución.

Principios en la iniciación del proceso

La iniciación del proceso debe cumplir con los siguientes principios:

1) El principio oficial o de la oficialidad, el delito es perseguible de oficio.

El ofendido tan sólo interviene en esta persecución como denunciante y posteriormente como testigo con dos limitaciones y una excepción : En cuanto a las limitaciones, la primera es que existen delitos que sólo pueden ser perseguidos por el ofendido, la segunda es que existen delitos que requieren autorización de un órgano político para iniciar su persecución. En cuanto a la excepción, viene establecido por el principio de la acción provocada (delitos leves o en que el interés público es insignificante).

2) El principio acusatorio.

En que es distinta la persona encargada de acusar ( Ministerio Público) de aquella que decide (Juez). Genera ello las siguientes consecuencias:

a) El tribunal no puede proceder de oficio.

b) El tribunal no puede extender el proceso pendiente a otras personas ni a otros hechos del mismo autor dependientes jurídicamente.

c) El órgano estatal competente para, la formulación de la acusación es la fiscalía (p.47).

3) El principio de la legalidad.

Significa el que la fiscalía debe practicar las investigaciones en caso de existir sospechas de haberse cometido un hecho delictivo. Está, asimismo, obligada a formular 
la acusación en caso que permanezcan suficientes sospechas acerca de ese hecho tras esas investigaciones. Este es un principio de carácter relativo pues la fiscalía persigue todo hecho punible.

4) El principio del juez legal.

No cabe posibilidad de sustracción al juez que conforme a las normas procesales corresponda conocer del asunto (p.48-49).

El juicio penal se inicia por descubrimiento oficial del delito (artículo 158 y 159 de la Ordenanza) o mediante un acto específico denominado "solicitud de persecución penal" (art. 158, 171 de la Ordenanza).

El Ministerio Público tiene la facultad de iniciar la acción penal bajo el principio de la legalidad. Éste se desglosa en dos, a saber, en las averiguaciones que obligatoriamente debe e ectuar la fiscalía y la obligatofriedad de deducir la acusación en caso que tras de la investigación se mantengan sospechas respecto del que ejecutó este hecho.

Existen ciertos casos en que no se hace obligatorio el acusar. Aquellos por hechos absolutamente irrelevantes, de mínima culpabilidad del autor ( $\mathrm{Al}$ respecto Jiménez de Asúa, La ley y el delito, 23, Abeledo- Perrot, Sudamericana, 1990). Lo mismo a los delitos relativamente irrelevantes, cuando carezca de importancia la consecuencia jurídica a imponer frente a las ya impuestas. Hechos punibles cometidos. en el extranjero o por extranjeros en que el interés público sea mínimo. En el caso de delitos leves, sustituyéndose la pena por condiciones y mandatos, etc.

En los delitos de acción privada rige el principio de oportunidad porque depende de la discrecionalidad de la fiscalía en la persecución de dichos delitos. Este principio es una exepción al de legalidad y la puede archivar directamente el proceso. El ejercicio de la acción depende de la aprobación del tribunal y después del ejercicio de la acción sólo se puede archivarla el tribunal aunque con autorización del fiscal.

El juez de control participa en el proceso penal alemán. La función de este juez es la de examinar si las medidas solicitados por el fiscal para investigar la autoría y ejecución del hecho punible es o no admisible jurídicamente. No examina la conveniencia de la medida y tampoco efectúa actividad jurisdiccional sino administrativa. Los supuestos de su intervención son si existe peligro en caso de retraso, actuando de propia iniciativa. Puede actuar a instancias de la fiscalía para provocar la interrupción de la prescripción y que queden asegurados los medios de prueba o en el caso en que es necesario practicar el interrogatorio bajo juramento de testigos o peritos, retirada provisional del permiso de conducir, prisión o internamiento provisional, etc.

La valoración de la prueba

En cuanto al tema de la prueba los principios informan esta actividad son los de averiguación, inmediación, el de libre apreciación y el indubio pro reo.

1) El principio de averiguación.

El tribunal, en su búsqueda a través de las pruebas de la verdad material, no queda ligado ni a las declaraciones de los participantes en el proceso, en concreto, a la confesión del acusado. Tampoco queda ligado a determinadas actitudes del imputado o a solicitudes probatorias interpuestas. Respecto de éstas puede ordenar la práctica de diligencias de pruebas que considere pertinentes. 
2) El principio de inmediación.

Este principio informa la vista de la causa ya que el tribunal debe dictar sentencia en base a su impresión personal del acusado y de las pruebas practicadas.

3) El principio de libre apreciación

Indica que no existe pruebas tasadas o de valoración legal.

La jurisprudencia alemana ha asentado las siguientes consecuencias y reglas sobre la materia : bajo juramento.

El tribunal es libre frente a las declaraciones testificales incluso las realizadas

El juez puede creer en lo que han declarado el acusado, frente a una mayoría de testigos de cargo juramentados.

El juez no está vinculado a ningún tipo de juramento.

El convencimiento del tribunal puede fundarse en prueba de indicios.

Existen, por cierto, limitaciones a este principio:

- El juez queda vinculado por las leyes del pensamiento y la experiencia.

- Todo inculpado puede rechazar la declaración o una parte de la misma en este caso debe valorarlo libremente pero en contra del declarante.

Este principio tiene exenciones en caso que se imputen delitos como injuria, por la exeptio veritatis y en otros de orden administrativo.

4) Indubio pro reo

En la duda la interpretación se hará en favor del reo. Expresión en Chile de este principio se presenta en la posibilidad que tiene el juez de absolver porque moralmente considera que existe excusa en la comisión del delito y ello genera el que su convencimiento no ha sido totalmente formado.

Con esto concluimos la rescención del texto escrito y traducido por el profesor Gómez Colomer. Indudablemente un trabajo como éste requeriría de un análisis quizá más extenso, sin embargo, a riesgo de no parecer suficiente el mismo, esperamos que lo aquí presentado sirva de aliciente a quienes deseen leer éste. Permítasenos señalar, por último, que tanto la traducción como la explicación del autor merecen un muy positivo calificativo ${ }^{1}$.

\footnotetext{
I Mención aparte merece el que este texto, además de constituir un auxilio para el jurista latinoamericano, es un paorte a la ciencia procesal de invaluable importancia. Incluso en la república Federal de Alemania el estudio del procedimiento ha sido desatendido de acuerdo a lo señalado por un distinguido profesor de la Universidad de Bonn, el Prof. Dr. Wolfgang Schöne (carta dirigida al autor en 1996).
} 